\title{
Persistent Memory Device
}

National Cancer Institute

\section{Source}

National Cancer Institute. Persistent Memory Device. NCI Thesaurus. Code C64579.

Any memory device that retains its stored data when the power is switched off. 